\title{
Dilemma of Asthma Treatment in Mild Patients
}

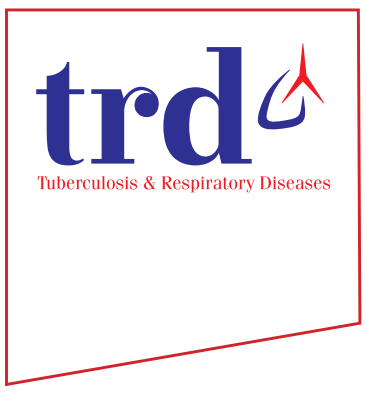

\author{
You Sook Cho, M.D., Ph.D. ${ }^{1}$ (iD) and Yeon-Mok Oh, M.D., Ph.D. ${ }^{2}$ (i) \\ Departments of ${ }^{1}$ Allergy and Clinical Immunology and ${ }^{2}$ Pulmonary and Critical Care Medicine, Asan Medical Center, \\ University of Ulsan College of Medicine, Seoul, Korea
}

Inhaled corticosteroids (ICSs) have been widely used as a key medication for asthma control. However, ICSs have been known to cause respiratory infections, such as pneumonia and pulmonary tuberculosis. Consequently, a dilemma exists regarding recommendation of persistent lifetime use of ICSs to mild asthma patients. Short-acting $\beta$-agonists (SABAs) have also been widely used for symptom relief. However, SABAs have been reported to increase the risk of asthma-related death, though incidences have been very rare. Consequently, a dilemma exists regarding recommendation of a SABA alone without an ICS or a controller to asthma patients even with very mild disease. In the real world, asthma patients tend to intermittently use ICS and more likely to be dependent on SABA since many patients want immediate relief of their symptoms. Consequently, a dilemma exists regarding the underuse of ICSs but the overuse of SABAs. One strategy for solving the presented dilemma would be identification of patients with asthma who require persistent use of asthma controllers. Such patients, who may be referred to as "persistent controller users," should continuously receive ICSs, even under controlled states of asthma. Another strategy would be a patient-adjusted, symptom-driven, intermittent-toregular treatment combining low-dose ICS/rapid-onset long-acting $\beta$-agonists instead of using a SABA alone or with lowdose ICS for the asthma patients with mild disease. Both of these two strategies could avoid the risky treatment of a SABA alone without an ICS and could reduce the dose of ICS with the maintenance of asthma control.

Keywords: Asthma; Therapeutics

\section{Introduction}

Asthma is a major disease with a high prevalence rate for all ages and a high mortality rate for the elderly ${ }^{1,2}$. Fortunately, the asthma medications have been developed over the last few

Address for correspondence: Yeon-Mok Oh, M.D., Ph.D.

Department of Pulmonary and Critical Care Medicine, Asan Medical

Center, University of Ulsan College of Medicine, 88 Olympic-ro 43-gil,

Songpa-gu, Seoul 05505, Korea

Phone: 82-2-3010-4651, Fax: 82-2-3010-6968

E-mail:ymoh55@amc.seoul.kr

Received: Feb. 9, 2018

Revised: Apr. 25, 2018

Accepted: Jul. 9, 2018

Published online: Sep. 28, 2018

(c) It is identical to the Creative Commons Attribution Non-Commercial License (http://creativecommons.org/licenses/by-nc/4.0/). The Korean Academy of Tuberculosis and Respiratory Diseases. decades and have imposed dramatic success on the history of modern medicines ${ }^{3}$.

Inhaled corticosteroids (ICSs), as an asthma controller, and short-acting $\beta$-agonists (SABAs), as a symptom reliever, are widely used for asthma management. However, these two inhaler medications have adverse effects which we should pay attention to.

In the real world, asthma patients tend to intermittently use ICS and more likely to be dependent on SABA since many patients want to immediate relief of their symptoms. Consequently, a dilemma exists regarding the underuse of ICSs but the overuse of SABAs has been observed.

\section{Success and Dilemma of ICSs}

\section{Effect of ICSs on reduction of asthma exacerbation}

The development of asthma controller medications (e.g., ICSs) is one of the most successful stories in modern medicine. Modern medicine has contributed widely in the man- 
agement of asthma, one of the leading respiratory diseases. Even in the early 1990s, patients with asthma exacerbations were more frequent in the emergency room. Some of them had to undergo airway intubation and mechanical ventilation. However, as the use of asthma controller medications in the early 2000s began to increase, the number of asthmatic patients who visited the emergency room decreased sharply, and the number of hospitalized asthmatic patients decreased even more, making it difficult to see asthmatic patients in the hospital wards.

\section{Efficacy of ICSs and recommendations by the guidelines for asthma management}

Asthma controller medications have proven to be efficacious in many aspects through large-scale observational studies and randomized clinical trials. ICSs, for example, have been shown to reduce asthma mortality, reduce asthma exacerbations, and improve asthma symptoms and lung function ${ }^{4}$.

Due to the proven strong efficacy, ICSs are recommended as the most important asthma controller medications in both international and domestic asthma guidelines ${ }^{5,6}$.

\section{Adverse effects of ICSs}

ICSs have been reported to have few adverse effects, unlike oral or injectable corticosteroids, but to increase the risk of adverse effects when used in high doses. For example, the risk for respiratory tract infections such as pneumonia, pulmonary tuberculosis, and non-tuberculous mycobacterial infections has been reported to increase ${ }^{7-9}$. It has also been reported that the risk of cataract increases and bone density slightly decreases $^{10-12}$.

\section{ICSs dilemma at the step 1 of mild asthma management}

Because the ICSs have adverse effects, it is recommended in the guidelines that if asthma is controlled, the treatment level should be lowered to reduce the dose of ICSs and to use the minimum maintenance dose. Furthermore, the guidelines state that asthma controller medications may not be used for the patient at the step 1 of mild asthma management. This strategy is advantageous in reducing the adverse effects of ICSs, but it also has the disadvantage in that the deterioration of asthma may not be prevented.

In particular, given the insufficient use of asthma controller medications, which is true in current practices, the recommendation of only SABAs without ICSs may not be appropriate.

\section{Success and Dilemma of SABAs}

\section{Rapid symptom improvement by SABAs}

SABAs (e.g., salbutamol in metered dose inhaler [MDI]) are not asthma controllers, but they have a rapid symptom-relieving effect and so have widely been used by asthma patients. For example, the salbutamol MDI, which is widely used in Korea, starts the action of bronchodilator is about 4 minutes, and reaches the peak at about 80 minutes $^{13}$.

Due to the rapid action of SABAs, it is advisable to use them when needed.

However, because SABAs do not have any anti-inflammatory effect but only have bronchodilation, they cannot prevent the asthma worsening and should be used as a temporary symptom reliever. Therefore, the asthma guidelines recommend that SABAs be used temporarily only when the asthma symptoms are worse ${ }^{5}$.

Although a SABA has the effect of promptly improving symptoms, it might cause asthma death, a rare but serious adverse effect. The adverse effect of asthma death problems was raised from the 1980s when the use of SABAs increased, and it has been repeatedly observed through large-scale observational studies ${ }^{14,15}$.

\section{Dilemma of SABAs at the step 1 of the asthma management guidelines}

At the step 1 of the asthma management guidelines, asthma patients with intermittent symptom may be treated only with a SABA ${ }^{5}$. However, the SABAs should not be encouraged to use only because the SABAs have no anti-inflammatory effect but have a rare but cardiac death ${ }^{16}$. Moreover, even mild asthma may change to moderate or severe during the disease course. Asthma is well known to be characterized by the variation of symptoms and also disease course. So the dilemma of SABAs at the step 1 of the asthma management should be solved.

\section{Strategies of Solutions for Asthma Treatment Dilemmas}

\section{Strategy of solution for the ICSs dilemma}

A solution strategy for the ICSs dilemma may be suggested with defining asthma patients who need a controller persistently. ICSs are a mainstay medication for asthma control but have some adverse effects as mentioned in this article. Considering the balance between the necessity and adverse effects of ICSs, persistent use of low dose ICS should be suggested the asthma patients who need a controller persistently. We may name the patient, a 'persistent controller user'. For the 
persistent controller user, a controller(s) should be used for a lifetime, because the necessity of controller (e.g., ICS) outweighs the adverse effects

Then, who are the persistent controller users? They may be the two groups of asthma patients (Table 1 and strategy 1 of Table 2). One is the group of patients at risk for exacerbation

Table 1. Suggested definition of persistent controller users

\begin{tabular}{|c|c|}
\hline & $\begin{array}{l}\text { Asthma patients requiring a controller medication(s) persis- } \\
\text { tently even under controlled }\end{array}$ \\
\hline & $\begin{array}{l}\text { Asthma patients with a high risk of exacerbation even under con- } \\
\text { trolled }\end{array}$ \\
\hline & Low $\mathrm{FEV}_{1}$, especially if $<60 \%$ predicted \\
\hline & Allergen exposure if sensitized; confirmed food allergy \\
\hline & $\begin{array}{l}\text { Sputum or blood eosinophilia; elevated FeNO in adults with } \\
\text { allergic asthma }\end{array}$ \\
\hline & Uncontrolled comorbidities like obesity or rhinosinusitis \\
\hline & Pregnancy \\
\hline & Ever intubated or in intensive care unit for asthma \\
\hline & $\geq 1$ severe exacerbation in last 12 months \\
\hline & $\begin{array}{l}\text { Asthma patients who have failed the trial of a controller discon- } \\
\text { tinuation }\end{array}$ \\
\hline
\end{tabular}

Adopted and modified from the GINA documents 2017, with permission from the GINA Committee ${ }^{5}$.

$\mathrm{FEV}_{1}$ : forced expiratory volume in 1 second. and the other is the group of patients who have failed the trial of a controller discontinuation.

Conversely, if an asthma patient is not the "persistent controller user," he or she will be able to try to discontinue the asthma controller. Even when discontinued, the asthma controller (e.g., a ICS) should be restarted whenever the asthma state is uncontrolled.

\section{Strategy of solution for the SABAs dilemma}

The SABAs dilemma may be solved by using a combined inhalation of ICS and rapid onset long acting $\beta$-agonist (LABA) (strategy 2 of Table 2). Asthma is a disease with its variation of course, good and bad, so it sometimes is necessary to use bronchodilator immediately when symptoms develop. However, as described above, the single use of $\beta$ agonist cannot be expected to have an anti-inflammatory effect, so there is a risk of asthma exacerbation and rarely asthma death. Therefore, O'Byrne et al. ${ }^{17}$ recently proposed to use a combined inhalation of ICS and rapid onset LABA (e.g., formoterol) at the earlier steps of asthma treatment. Formoterol is an example of the rapid onset LABA, which is known to start its effect at 5 minutes and peak at about 2 hours due to its short onset time $^{13}$.

The main advantage of the combined ICS and rapid onset LABA together is that it can prevent the risk of asthma death albeit rare. In addition, we can use the combination of ICS and rapid onset LABA in a single device with convenience compared to using the two inhalers separately. So from the step 1

Table 2. Step-wise asthma treatment comparing a current guideline to strategies for solutions of asthma treatment dilemma

\begin{tabular}{|c|c|c|c|c|c|}
\hline \multirow[b]{2}{*}{ Step } & \multicolumn{2}{|c|}{ Current guideline* } & \multicolumn{2}{|c|}{ Strategy 1} & Strategy 2 \\
\hline & Preferred controller & Reliever & $\begin{array}{l}\text { Preferred } \\
\text { controller }\end{array}$ & Reliever & $\begin{array}{l}\text { Preferred } \\
\text { controller }\end{array}$ \\
\hline Step 3 & Low-dose ICSs/LABAs & & & & \\
\hline Step 4 & $\begin{array}{l}\text { Medium/high ICS/ } \\
\text { LABA }\end{array}$ & $\begin{array}{l}\text { SABA as needed or } \\
\text { low-dose ICSs/ } \\
\text { rapid-onset LABAs }\end{array}$ & & $\begin{array}{r}\text { Same as the } \\
\text { (see the column }\end{array}$ & $\begin{array}{l}\text { current guideline } \\
\text { of Current guideline) }\end{array}$ \\
\hline Step 5 & $\begin{array}{l}\text { Refer to add-on treat- } \\
\text { ment }\end{array}$ & & & & \\
\hline
\end{tabular}

*Adopted and modified from the Korean Asthma Guideline 2014, according to the Creative Commons license Korean Academy of Tuberculosis and Respiratory Diseases ${ }^{6}$. ${ }^{\dagger}$ For persistent controller users. ${ }^{*}$ The strategy might be applied from the step 1 to some cases of the step 2 in the Asthma Guideline. ${ }^{s}$ Formoterol is an example.

ICS: inhaled corticosteroids; SABA: short-acting $\beta 2$ agonist; LABA: long acting $\beta 2$ agonist. 
to some cases of the step 2, patients may by themselves adjust the use of low dose ICS/rapid onset LABA from intermittent to regular. This patient-adjusted symptom-driven intermittent to regular treatment with low dose ICS/rapid onset LABA would be one strategy of solution to solve the dilemma ${ }^{18}$.

\section{Conclusion}

ICSs and SABAs, which are key medications for asthma treatment, are widely used as an asthma controller and a symptom reliever, respectively. Because of adverse effects, there is a dilemma that is difficult to recommend for a persistent lifetime use of ICS for mild asthma patients. In this article, we suggested that the ICSs dilemma should be solved by defining a 'persistent controller user' who should use the ICS persistently and that the SABAs dilemma might be solved by using patient-adjusted symptom-driven intermittent to regular treatment with low dose ICS/rapid onset LABA to mild asthma patients at the step 1 and some patients of the step 2 .

Both of these two strategies could avoid the risky treatment of a SABA alone without an ICS and could reduce the dose of ICS with the maintenance of asthma control.

\section{Authors' Contributions}

Conceptualization: Cho YS, Oh YM. Article searching and curation: Oh YM. Review of the articles: Cho YS, Oh YM. Writing - original draft preparation: Oh YM. Writing - review and editing: Cho YS, Oh YM. Approval of final manuscript: Cho YS, Oh YM.

\section{Conflicts of Interest}

No potential conflict of interest relevant to this article was reported.

\section{References}

1. Korean Institute for Health and Social Affairs. Prevalence of asthma like symptoms in Korean adult population. Korean J Med 2001;60:196-205.

2. Global Asthma Network. The global asthma report 2014 [Internet]. Global Asthma Network; 2014 [cited 2017 Dec 29]. Available from: http://www.globalasthmareport.org/burden/ mortality.php.

3. Barnes PJ. New drugs for asthma. Semin Respir Crit Care Med 2012;33:685-94.
4. Suissa S, Ernst P, Benayoun S, Baltzan M, Cai B. Low-dose inhaled corticosteroids and the prevention of death from asthma. N Engl J Med 2000;343:332-6.

5. Global Initiative for Asthma. Global strategy for the diagnosis and prevention [Internet]. Global Initiative for Asthma; 2017 [cited 2017 Dec 29]. Available from: https://ginasthma.org/.

6. Kim DK, Park YB, Oh YM, Jung KS, Yoo JH, Yoo KH, et al. Korean asthma guideline 2014: summary of major updates to the Korean asthma guideline 2014. Tuberc Respir Dis 2016;79:111-20.

7. Brode SK, Campitelli MA, Kwong JC, Lu H, Marchand-Austin A, Gershon AS, et al. The risk of mycobacterial infections associated with inhaled corticosteroid use. Eur Respir J 2017;50:1700037.

8. Lee CH, Kim K, Hyun MK, Jang EJ, Lee NR, Yim JJ. Use of inhaled corticosteroids and the risk of tuberculosis. Thorax 2013;68:1105-13

9. Qian CJ, Coulombe J, Suissa S, Ernst P. Pneumonia risk in asthma patients using inhaled corticosteroids: a quasi-cohort study. Br J Clin Pharmacol 2017;83:2077-86.

10. Smeeth L, Boulis M, Hubbard R, Fletcher AE. A population based case-control study of cataract and inhaled corticosteroids. Br J Ophthalmol 2003;87:1247-51.

11. Hanania NA, Chapman KR, Sturtridge WC, Szalai JP, Kesten S. Dose-related decrease in bone density among asthmatic patients treated with inhaled corticosteroids. J Allergy Clin Immunol 1995;96(5 Pt 1):571-9.

12. Zhang L, Prietsch SO, Ducharme FM. Inhaled corticosteroids in children with persistent asthma: effects on growth. Cochrane Database Syst Rev 2014;(7):CD009471.

13. van Noord JA, Smeets JJ, Maesen FP. A comparison of the onset of action of salbutamol and formoterol in reversing methacholine-induced bronchoconstriction. Respir Med 1998;92:1346-51.

14. Crane J, Pearce N, Flatt A, Burgess C, Jackson R, Kwong T, et al. Prescribed fenoterol and death from asthma in New Zealand, 1981-83: case-control study. Lancet 1989;1:917-22.

15. Suissa S, Ernst P, Boivin JF, Horwitz RI, Habbick B, Cockroft D, et al. A cohort analysis of excess mortality in asthma and the use of inhaled beta-agonists. Am J Respir Crit Care Med 1994;149(3 Pt 1):604-10.

16. Suissa S, Hemmelgarn B, Blais L, Ernst P. Bronchodilators and acute cardiac death. Am J Respir Crit Care Med 1996;154(6 Pt 1):1598-602.

17. O'Byrne PM, Jenkins C, Bateman ED. The paradoxes of asthma management: time for a new approach? Eur Respir J 2017;50:1701103.

18. Beasley R, Weatherall M, Shirtcliffe P, Hancox R, Reddel HK. Combination corticosteroid/beta-agonist inhaler as reliever therapy: a solution for intermittent and mild asthma? J Allergy Clin Immunol 2014;133:39-41. 